\title{
Biofuel Research Journal
}

Biofuel Research Journal (BRJ) is an open access online journal and completely free-of-charge publishes original articles, review articles, case studies, book reviews, short communications, and hypotheses on the fundamentals, applications, processing, and management of biofuels technologies.

The journal's aim is to advance and disseminate knowledge in all the biofuel-related areas of biodiesel, bioethanol, biobuthanol, biogas, biomass, algae, bioreactions, bioreactors, membrane-bioreactors, fermentation, biorefinery (e.g. membrane separation technology), bioprocess, applied microbiology, combustion, and bioresource technologies associated with conversion or production of biofuels. Moreover, novel and integrated biofuel processing and hybrid systems as well as energy audit for biofuel production plants are of interest. The journal also seeks to publish articles with a focus on the application of artificial photosynthesis for biofuels production, carbon footprint analysis, strategies for limiting green house gas (GHG) emissions, life cycle assessment (LCA) and exergy analysis of biofuel production/application pathways, compliance with the international standards (such as PAS 2050:2011 and ISO 14040:2006), technoeconomic analysis of biofuel production/application, impacts of biofuels production/consumption on climate change, futuristic pathways for biofuels production, and promotion of biofuel applications in the developing world for indigenous development.

BRJ calls for papers that cover the following fields:

Biofuels: biodiesel, bioethanol, biobuthanol, biogas, etc.

Biofuels production, modeling, and economics

Bioprocesses and bioproducts: Bioreactions, biocatalysis, bioreactors, membrane-bioreactors, modeling and optimization, scale-up, supercritical technology, ionic liquids, and fermentations.

Biomass and feedstock utilization: Bioconversion of agro-industrial residues.

Biorefinery: Membrane separation technology, adsorption, solvent-extraction, etc.

Environmental protection: Simultaneous biological waste treatment and biofuels production, clean development mechanism.

Thermochemical conversion of biomass: Combustion, pyrolysis, gasification, catalysis.

Algal biofuels and energy crops including energy crops genetic engineering

Application of artificial photosynthesis for biofuels production

Carbon foot-printing analysis and strategies for limiting green house gas (GHG) emissions: Life cycle assessment (LCA) analysis of biofuel production/application pathways and Compliance with the international standards (such as PAS 2050:2011 and ISO 14040:2006).

Exergy analysis of biofuel production/application pathways

Technoeconomic analysis of biofuel production/application

Impacts of biofuels production and consumption on climate change

Futuristic pathways for biofuels production

Biofuel applications in the developing world for indigenous development

BRJ also covers the following fields:

- Process scale-up and economic analysis

- Process integration and zero discharge strategies

- Resource recovery

- Water-energy balance improvements

- Energy audit for biofuels production plants

\section{Editor-in-Chief}

Assist. Professor Meisam Tabatabaei, Biofuel Research Team (BRTeam), Agricultural Biotechnology Research Institute of Iran (ABRII), Karaj, Iran, Tel: +98 9132865342 , E-mail: meisam_tabatbaei@abrii.ac.ir

International Advisory Board Members

Professor Yusuf Chisti, School of Engineering, Massey University, Private Bag 11222, Palmerston North, New Zealand, Tel: +64 63505934 , E-mail: y.chisti@massey.ac.nz

Professor Ahmad Fauzi Ismail, Advanced Membrane Technology Research Centre (AMTEC), Universiti Teknologi Malaysia 81310 , Skudai, Johor, Malaysia, Tel: +60 75535592 , E-mail: afauzi@utm.my

Professor Seeram Ramakrishna, Mechanical Engineering Department, National University of Singapore (NUS), Singapore, Tel: +65 6516 2216 , E-mail: seeram@nus.edu.sg

Professor Solange I. Mussatto, Novo Nordisk Foundation Center for Biosustainability, Technical University of Denmark, Denmark, Tel.: +45 93511891, E-mail: smussatto@biosustain.dtu.dk

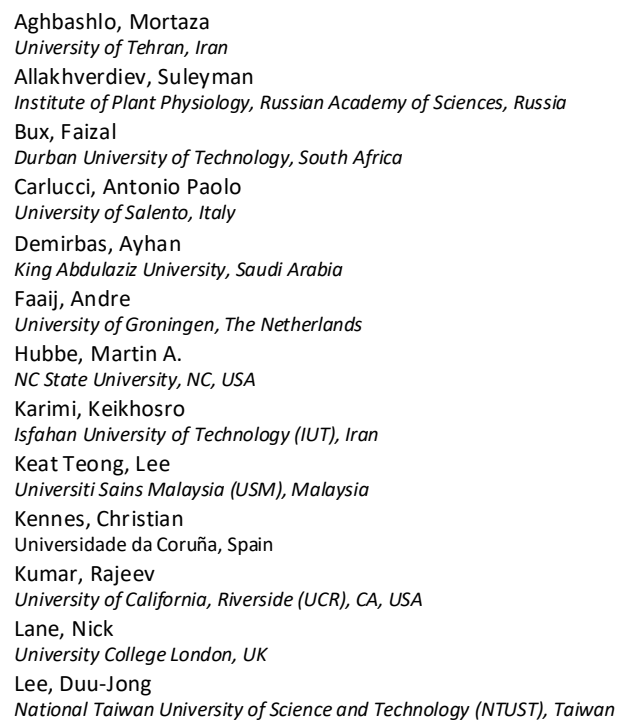

\section{Editorial Board Members}

Luque, Rafae

Universidad de Córdoba, Spain

Matsuura, Takeshi

University of Ottawa, Canada

Montgomery, Hugh

University College London, UK

Najafpour, Mohammad Mahdi

Institute for Advanced Studies in Basic Sciences, Iran

Pandey, Ashok

CSIR-National Institute for Interdisciplinary Science and Technology, India

Pant, Deepak

VITO-Flemish Institute for Technological Research, Belgium

Ruiz, Héctor A.

Autonomous University of Coahuila, Mexico

Singhania, Reeta Rani

Center for Advanced Bioenergy Research, $1 O C L$ R \& D Faridabad, India

Taherzadeh, Mohammad J

University of Borås, Borås, Sweden

Van Loosdrecht, Mark

Delft University of Technology, The Netherlands

Wang, Yong

Washington State University, USA

Watts, Nick

University College London, UK

Yang, Yi

University of Minnesota, USA

Publication Policy

Biofuel Research Journal (ISSN 2292-8782). Articles published in Biofuel Research Journal are published at no processing charge and will be Open-Access articles distributed completely free-of-charge under the terms and conditions of the Creative Commons Attribution License. 